\title{
Technology Integration to English Speaking for Beginner Classroom Through Vlogs: A Bridge of EFL Students' Hesitancy to Speak
}

\section{Syifa' Khuriyatuz Zahro}

Universitas Islam Darul ‘Ulum, Lamongan

\section{Abstract}

The current advancement of video-blogs (vlogs) in YouTube channel among students of generation $z$ has challenged teachers to make use of its potential for students' speaking enhancement. The present research aimed at elaborating the implementation of educational vlogs as well as lecturers' and students' perceptions in response to the use and the creation of educational vlogs to enhance their speaking proficiency and reduce their speaking hesitancy. The research piloted to university students who attended speaking for beginner course in Lamongan. This is mixed-method research employed 27 students who were purposefully selected as the sample

Corresponding Author: Syifa' Khuriyatuz Zahro syifazahro@unisda.ac.id

Received: 17 February 2020 Accepted: 20 February 2020 Published: 27 February 2020

Publishing services provided by Knowledge E

(c) Syifa' Khuriyatuz Zahro. This article is distributed under the terms of the Creative Commons Attribution License, which permits unrestricted use and redistribution provided that the original author and source are credited.

Selection and Peer-review under the responsibility of the Isolec Conference Committee.

\section{S OPEN ACCESS}

\section{Introduction}

The idea of technology integration to learning activities has been currently sought, investigated, and applied by many education practitioners. Studies have found plentiful advantages to use technology in integration to the education field (Alsied \& Pathan, 2013) including language learning as speaking English. Developing students' English speaking skills require them to talk in and out of classroom activities confidently without hesitancy. Moreover, 21st-century fast development has provided various advanced technological media that have been considered as one of worthwhile means to enhance speaking skills (Bahadorfar \& Omidvar, 2014).

Speaking for beginner is two credits speaking course enrolled by English education department students in the first semester who are of $\mathbf{Z}$ generation who were born between 1997-2000 with special characteristics in technology, internet, laptop, and 
mobile phone literate. The sophisticated characteristic is suitable for the idea of technology integration to the speaking for beginner course. The preliminary study to the students showed that $67 \%$ of them found difficult to speak English for the reason of the lack of self-confidence (55\%) and fear to make mistake (45\%).

One of the ideas for technological media Integration to English speaking activity is by assigning students to create a video recording of their speaking skills through videoblogging (vlogging). Rahmawati, Harmanto, \& Indriastuti (2018) found that the students become active, more interested, and confident to practice speaking English by vlogging. More specifically, Maulidah (2018) asserted the significant enhancement of vlogs' implementation on students' speaking skills, especially to promote their presentation and speaking performances with the help of more speaking exercises while creating the video so that builds their autonomous learning.

Relating vlogs to English speaking activities have been extensively applied and studied in recent years at various learners' speaking levels. The study yielded a positive enhancement in students' speaking skill, motivation and confidence to speak English (Rahmawati et al., 2018; Wulandari, 2019) and suggested four significances of the impact of vlogs; students' encouragement, self-presentation, talk more time and autonomous learning (Sun, 2009). Meanwhile, the result of perception inquiry generated students' pleasant perception toward English vlogs to develop speaking skills (Kurniawan, 2019; Safitri \& Khoiriyah, 2017).

Based on the aforementioned explanation, this study is expected as a bridge of the above students' speaking problems by relating the activity to their sophisticated characteristics. Therefore, the present research is oriented to examine the implementation of vlogs, the lecturers' perception of the use of vlogs, students' perception in response to the use and the creation of vlogs as a medium to enhance their speaking proficiency and reduce their speaking hesitancy.

\section{Method}

The research is a mixed-method-based investigation conducted to lecturers and students who attended speaking for beginner course on three private universities in Lamongan at the English education department. Among 54 students who participated in the study, 27 of them were purposefully selected as the sample in line with three speaking proficiency levels, good, average and less than average, to avoid bias. Additionally, three lecturers also took part in the study as the guide of vlogs' creation and provided ample insight into the vlogs' implementation. 
The study was initiated by collecting the data through the pre-test that was employed by the lecturers who were asked to test students speaking before implementing vlogs. Subsequently, the researchers observed the process and progression of vlogs implementation in speaking classroom as a non-participant observer by taking notes of some important happenings. Then, after several meetings and guidance to create vlogs, the lecturers assigned students to create two vlogs about description people or things as the mid-term project focusing on present tense and vlogs about daily or weekend activities as the final project emphasizing on the use of present, past and future tense. Subsequently, the lecturers were asked to assess each students' vlogs as the post-test score. To generate equality of speaking assessment among the lectures, the pre-test, vlog 1 and post-test were analyzed by a speaking rating scale as used by Wulandari (2019) that consisted of 5 elements; pronunciation, fluency, vocabulary, syntax and the use of target language.

Next, a survey was conducted by distributing a questionnaire adapted from (Kurniawan, 2019) to the students to know their perception on the vlogs' implementation and creation. Additional data were also taken through a semi-structured interview with the lecturers of speaking for beginner that was generally guided by interview guidance adapted from Djahida (2017) to reveal their opinion of the vlog implementation in speaking class.

As a final phase, the data analysis was accomplished to the obtained data. The numeric data pre and post-test were analyzed statistically by a paired sample t-test through SPSS 22. To analyze the questionnaire, three points Likert scale was applied. Meanwhile, the data gained from the observation and interview was described in a qualitative way to generate lecturers' and students' attitudes on vlogs' implementation and creation.

\section{Findings and Discussions}

The objective of speaking for beginner course is to improve the students' ability to speak accurately in particular themes: describing things (people, places, and things) and telling current, past and future events (self and other experiences). The aforementioned tenses are the accuracy element focus that must be mastered by the students at the end of the course. The fluency and pronunciation practice was done in an in-class activity that was observed dissatisfactory. Therefore, the students are expected to improve their speaking accuracy and fluency by creating vlogs outside the class where students can 
practice to use the tense all together confidently without afraid of making mistake in an assignment of "a vlog creation".

\subsection{The Implementation of Vlogs in Speaking for Beginner Course}

The implementation of vlogs in the speaking for beginner course was initiated by watching English native speaker's vlog taken from YouTube about describing self-travel at the sixth meeting in week 6 . Watching vlog was expected to give students' a depiction of how does vlog look like and introduce them vlogging activity so they were able to imitate the vlogs flow. Subsequently, they were asked to perform "introducing themselves and describing the activity they are going to explain" as an introduction part of a vlog by focusing on the present and present continuous tense. At first, they were suggested to imitate the vlogger way of speaking, like how to greet people and introduce themselves and telling their planned activity. The students were expected to be able to apply what they had learned at the preceding three weeks meeting about describing people, places, and things. At the end of the meeting, the students were assigned to make a short vlog about one of the following general themes: describing people, places, or things as their mid-term assessment. The students speaking performance in their vlogs were formerly assessed by the lecturer to obtain students' speaking mid-term score. The mid-term score was then called the vlog 1 score.

In week 8, the lecturer asked students to evaluate the vlogs as well as state the obstacles they faced in creating vlogs. The obstacles are self-confidence and hesitancy to talk to a camera that made some of them read the written script, boisterous voice production for video recording in public places, limited skill in editing the vlog, vlogs' free length made some of the vlogs showed the video without their speaking practice. To overcome the obstacles, the researcher asked the lecturers to give instruction that was more specific in the following project of vlog creation. The instruction was 1) you are assigned to video-record yourself telling your current activity in English, 2) you can use a headset to make your voice clearer, 3) your video must not exceed 4 minutes, 4) Any kind of reading a script while video recording will be graded zero. Meanwhile, an extra class (out of fourteen meetings) of a workshop was held to give them the additional skill of editing video in creating vlogs through software or mobile apps.

For a final evaluation of speaking for beginner course, the students were asked to create vlogs of their weekend activity by applying present, past and future tense. The vlogs creation in the final project was then called vlog 2 following the abovementionedinstruction. The additional instruction was that students were required to upload their 
vlog 2 in the YouTube channel created by the lecturer to give them more challenge to create the best vlogs as it would be watched by many viewers on social media, YouTube. The vlogs 2 were then also assessed by the lecturer to get the vlog 2 scores.

Furthermore, the result of a paired sample t-test with statistic calculation described as follow:

\begin{tabular}{|c|c|c|c|c|c|}
\hline & & Mean & $N$ & Std. Deviation & $\begin{array}{l}\text { Std. Error } \\
\text { Mean }\end{array}$ \\
\hline \multirow[t]{2}{*}{ Pair 1} & pretest & 73,70 & 27 & 7,124 & 1,371 \\
\hline & postest & 80,11 & 27 & 5,774 & 1,111 \\
\hline
\end{tabular}

Figure 1: Paired Samples Statistics

\begin{tabular}{|c|c|c|c|c|c|c|c|c|}
\hline & \multicolumn{5}{|c|}{ Paired Differences } & \multirow[b]{3}{*}{$t$} & \multirow[b]{3}{*}{ df } & \multirow[b]{3}{*}{ Sig. (2-tailed) } \\
\hline & \multirow[b]{2}{*}{ Mean } & \multirow[b]{2}{*}{ Stc. Deviation } & \multirow{2}{*}{$\begin{array}{l}\text { Std. Error } \\
\text { Mean }\end{array}$} & \multicolumn{2}{|c|}{$\begin{array}{l}\text { 95\% Confidence Interval of the } \\
\text { Difference }\end{array}$} & & & \\
\hline & & & & Lower & Upper & & & \\
\hline Pair 1 pretest-postest & $-6,407$ & 2,777 & .534 & $-7,506$ & $-5,309$ & $-11,969$ & 26 & .000 \\
\hline
\end{tabular}

Figure 2: Paired Samples Test

The abovementioned Figure 1 showed an improvement between the score in the pretest, $M=73.70$ and post-test, $M=80.11$. Meanwhile, Figure 2 displayed the $t$-value= 11.989 greater than $\mathrm{t}$-table $=2.056$. Both data has verified that the vlogs integration to speaking for beginner classroom significantly enhanced students' speaking ability, especially for those classified as having average and less than average ability in speaking as revealed by the lecturers in the interview.

\subsection{The Perception of the Use and the Creation of Vlogs}

A sum of ten statements in the questionnaire about the vlogs creation generated that in general students have positive attitudes toward vlogs implementation in speaking for beginner course. The questionnaire was responded in $82 \%$ positively that was enforced previous research result that found out students satisfying perception of vlogs (Kurniawan, 2019; Rahmawati et al., 2018; Sun, 2009). Meanwhile, 8\% belongs to the negative perception and neutral perception was $10 \%$. The more specific percentage of each statement can be displayed in the following table.

The aforementioned table clearly shows in what way $74 \%$ of the students were comfortable by vlogs assignment and they learned more pronunciation practice. Moreover, about $81 \%$ of them learned to be good English speakers and believed that vlogging was effective to encourage them to use English outside the class. Additionally, $89 \%$ of them 
TABLE 1: The Students' Perception of Vlogs Creation

Statements: Students' Perception
1. I feel more comfortable learning English by creating vlogs
2. It is easy to learn English through vlogs creation
3. I can practice English communication more through creating vlogs
4. I learn more pronunciation practice through vlogging
5. My confidence increases while learning English through creating
vlogs
6. My fluency in English speaking improved because of vlogging
7. I learn to be a good English speaker through vlogs creation
8. Vlogging is more enjoyable than traditional classroom learning
9. Vlogging task is effective to encourage me using English outside
the class
10. I get positive impact on my speaking ability by vlogging

\begin{tabular}{|c|c|c|}
\hline \multicolumn{3}{|c|}{ Responses } \\
\hline A (\%) & N (\%) & DA (\%) \\
\hline 74 & 11 & 15 \\
\hline 30 & 19 & 52 \\
\hline 89 & 7 & 4 \\
\hline 74 & 19 & 7 \\
\hline 93 & 7 & 0 \\
\hline 89 & 7 & 4 \\
\hline 81 & 7 & 11 \\
\hline 93 & 7 & 0 \\
\hline 81 & 11 & 7 \\
\hline 93 & 7 & 0 \\
\hline
\end{tabular}

were able to practice to communicate with others in English more and improve their fluency, as well as $93 \%$ of them, enjoyed the vlogging more than a traditional classroom, got a positive impact on their speaking skills and increased their confidence to speak English.

The high amount of percentage in students' confidence improvement to speak English supported previous related research that consistently found the students' confidence improvement while vlogging (Kurniawan, 2019; Rahmawati et al., 2018; Wulandari, 2019). Therefore, this finding was subsequently investigated more in the interview to both the lecturers and the students. The lecturers confirmed that the high amount of students' confidence in speaking English was consistent with the students' speaking scores of vlog 2 that were mostly improved. They added that most of the hesitant speakers within in-class speaking activity got more scores through vlogs 2 . The students' interview resulted in their confession of confidence level's progress while speaking through vlogging rather than speaking within the in-class activity that made them hesitant to speak.

Unfortunately, the confidence enhancement was antonymous to the issue of vlog creation difficulty. The survey indicated $52 \%$ of students felt difficult to learn English through vlogs creation. One of the difficulties identified in the interview session is the lengthy process of creating vlogs. Some of the interviewees admitted that they could not take the video recording only once, they must retake for other shoots to get the best video they intended. The activity of retaking the video recording for several times was a 
process of students' self-evaluation and practice to speak English more. The repetition was a meaningful activity to enhance their speaking skills in terms of their fluency and accuracy. This is synonymous with Sun (2009), Maulidah (2018) and Wulandari (2019) who pointed out recording videos particularly vlogging has influenced students' learning independence and built their self-evaluation to be more critical of their fluency and accuracy in speaking skill.

Another difficulty is the Internet connection to integrate vlog 2 to the YouTube channel. The obligation that required high speed of the internet somehow disturbed their enjoyment in vlogging. This issue was also identified previously by Wulandari (2019) as the limitation of vlogs concerning social media integration. Furthermore, the last issue of students' difficulty in vlogging is as mentioned in the observation that limited skill in editing the vlog still disturbed their vlog creation. Hence, they need to learn more about editing video skills to make their vlogs more interesting and future research may need to consider this technical limitation.

\section{Conclusions and Suggestions}

The aforementioned findings and discussions lead to the conclusion that integrating vlogs to speaking classroom mostly have positive feedback from both lecturers and students, particularly as a bridge the hesitant students' confidence. Therefore, it is suggested to utilize the medium toward English classroom in speaking classroom or may be applied to other different skills by considering some technical limitations, like vlogs' lengthy process, internet connection in social media integration and students' limited skill in video editing.

\section{References}

[1] Alsied, S. M., \& Pathan, M. M. (2013). The use of computer technology in EFL classroom: Advantages and implications. International Journal of English Language \& Translation Studies (IJ-ELTS), 1(1), 61-71.

[2] Bahadorfar, M., \& Omidvar, R. (2014). Technology in teaching speaking skill. Acme International Journal of Multidisciplinary Research, 2(4), 9-13.

[3] Djahida, L. (2017). The role of educational YouTube videos in improving EFL learners' speaking skill: The case of second year LMD students of English at Biskra University. Retrieved from http://dspace.univ-biskra.dz:8080/jspui/bitstream/ 123456789/10066/1/Labdi-Djahida2017pdf.pdf 
[4] Kurniawan, I. (2019). Student's Perception on the Use of Youtube as a Learning Media to improve their speaking skill T. In International Seminar and Annual Meeting BKSPTN Wilayah Barat (pp. 324-329).

[5] Maulidah, I. (2018). Vlog: the Mean to Improve Students' Speaking Ability. In Proceedings of the International Conference on English Language Teaching (ICONELT 2017) (pp. 12-15).

[6] Rahmawati, A., Harmanto, B., \& Indriastuti, N. R. (2018). The Use of Vlogging to improve the Students' Speaking Skill. EDUPEDIA, 2(1), 87-95.

[7] Safitri, N., \& Khoiriyah, I. (2017). Students' Perceptions on the Use of English Vlog (Video Blog) to Enhance Speaking Skill. In The Fifth Asian Academic Society International Conference (pp. 240-247).

[8] Sun, Y.-C. (2009). Voice blog: An exploratory study of language learning. Language Learning \& Technology, 13(2), 88-103.

[9] Wulandari, M. (2019). Improving EFL learners' speaking proficiency through Instagram vlog. LLT Journal: A Journal on Language and Language Teaching, 22(1), 111-125. 